\title{
Earthquake input energy to tall and base-isolated buildings in time and frequency dual domains
}

\author{
AUTHOR(S): \\ Takewaki, Izuru; Fujita, Kohei
}

\section{CITATION:}

Takewaki, Izuru ... [et al]. Earthquake input energy to tall and base-isolated buildings in time and frequency dual domains. Structural Design of Tall and Special Buildings 2009, 18(6): 589-606

ISSUE DATE:

2009-10

URL:

http://hdl.handle.net/2433/89630

\section{RIGHT:}

c 2009 John Wiley \& Sons, Ltd.; この論文は出版社版でありません。引 用の際には出版社版をご確認ご利用ください。; This is not the published version. Please cite only the published version. 


\title{
Earthquake Input Energy to Tall and Base-isolated Buildings in Time and Frequency Dual Domains
}

\author{
Izuru Takewaki ${ }^{1}$ and Kohei Fujita ${ }^{2}$ \\ Department of Urban \& Environmental Engineering, Graduate School of Engineering, \\ Kyoto University, Kyotodaigaku-Katsura, Nishikyo-ku, Kyoto 615-8540, Japan
}

\begin{abstract}
Earthquake input energies to tall and base-isolated buildings are examined by both time-domain and frequency-domain methods. Both methods support the validity of evaluating the earthquake input energy each other. It is shown that both methods have different advantages and can compensate for each other. While the time-domain method has a long history and is applicable to non-linear models as well, the frequency-domain method is characterized by the energy transfer function and its equi-area property plays an important role in the discussion of the stability of earthquake input energy. This equi-area property can be derived by the residue theorem only in a simple model. It is also demonstrated that this equi-area property in multi-degree-of-freedom models can be derived by the time-domain method for an idealized model of input motions with a constant Fourier amplitude spectrum. This idea is applied to tall and base-isolated buildings. The equiarea property of the energy transfer function provides a stable characteristic on the input energy as far as the total mass of the buildings is constant.
\end{abstract}

KEY WORDS: Earthquake input energy, Frequency-domain analysis, Time-domain analysis, Residue theorem, Energy transfer function, Base-isolation, Tall buildings, Energy spectrum

\footnotetext{
${ }^{1}$ Professor, corresponding author, e-mail: takewaki@archi.kyoto-u.ac.jp

${ }^{2}$ Graduate student
} 


\section{Introduction}

A lot of work have been accumulated on the topics of earthquake input energy to building structures (for example, Housner 1959; Zahrah and Hall 1984; Akiyama 1985; Uang and Bertero 1990; Leger and Dussault 1992; Kuwamura et al. 1994; Ordaz et al. 2003; Takewaki 2004a, b, 2005a, b, 2006, 2007a, b). In some countries the earthquake input energy has been employed as an earthquake input demand. The earthquake input energy has usually been computed in the time domain. The time-domain approach has several advantages, e.g. the availability in non-linear structures, the description of time-history response of the input energy, the possibility of expressing the input energy rate. On the other hand, the time-domain approach is not necessarily appropriate for probabilistic and bound analysis under uncertainties (Takewaki 2004a, 2005b, 2006). For that purpose, the frequency-domain approach (Lyon 1975, Ordaz et al. 2003, Takewaki 2004a, b, 2005a, b, 2006, 2007a, b) is suitable because it uses the Fourier amplitude spectrum of input ground accelerations and the time-invariant energy transfer functions of the structure.

This paper is aimed at demonstrating that (1) the time-domain and frequency-domain methods have different advantages and can support each other and (2) the equi-area property of the energy transfer function in general structural models can be derived by the timedomain method for an idealized model of input motions with a constant Fourier amplitude spectrum. This idea is applied to tall and base-isolated buildings. It is shown that the equi-area property of the energy transfer function provides a stable characteristic on the input energy as far as the total mass of the buildings is constant. The property of energy spectra is also investigated for several recorded ground motions including near-field and farfield ground motions by using the frequency-domain method.

\section{Earthquake Input Energy to SDOF Model}

Consider a damped linear single-degree-of-freedom (SDOF) system of mass $m$, stiffness $k$ and damping coefficient $c$, as shown in Figure 1 . Let $\Omega=\sqrt{k / m}$, $h=c /(2 \Omega m)$ and $x$ denote the undamped natural circular frequency, the damping ratio and the displacement of the mass relative to the ground, respectively. The time derivative is 
denoted by an over-dot. The input energy to this SDOF system by a uni-directional ground acceleration $\ddot{u}_{g}(t)$ from $t=0$ to $t=t_{0}$ (end of input) can be defined by the work of the ground on the structural system and is expressed by

$$
E_{I}=\int_{0}^{t_{0}} m\left(\ddot{u}_{g}+\ddot{x}\right) \dot{u}_{g} \mathrm{~d} t
$$

Integration by parts of Equation (1) provides

$$
\begin{aligned}
E_{I} & =\int_{0}^{t_{0}} m\left(\ddot{x}+\ddot{u}_{g}\right) \dot{u}_{g} \mathrm{~d} t=\int_{0}^{t_{0}} m \ddot{x}_{g} \mathrm{~d} t+\left[\frac{1}{2} m \dot{u}_{g}{ }^{2}\right]_{0}^{t_{0}} \\
& =\left[m \dot{x} \dot{u}_{g}\right]_{0}^{t_{0}}-\int_{0}^{t_{0}} m \dot{x} \ddot{u}_{g} \mathrm{~d} t+\left[\frac{1}{2} m \dot{u}_{g}{ }^{2}\right]_{0}^{t_{0}}
\end{aligned}
$$

If $\dot{x}=0$ at $t=0$ and $\dot{u}_{g}=0$ at $t=0$ and $t=t_{0}$, the input energy can be reduced to

$$
E_{I}=-\int_{0}^{t_{0}} m \ddot{u}_{g} \dot{x} \mathrm{~d} t
$$

It is known (Lyon 1975; Ordaz et al. 2003; Takewaki 2004a, b, 2005a, b, 2006, 2007a, b) that the input energy per unit mass can also be expressed in the frequency domain.

$$
E_{I} / m=\int_{0}^{\infty}\left|\ddot{U}_{g}(\omega)\right|^{2} F(\omega) \mathrm{d} \omega
$$

where $F(\omega)=-\operatorname{Re}\left[H_{V}(\omega ; \Omega, h)\right] / \pi$ and $H_{V}(\omega ; \Omega, h)$ is the transfer function defined by $\dot{X}(\omega)=H_{V}(\omega ; \Omega, h) \ddot{U}_{g}(\omega) . \quad \dot{X}$ and $\ddot{U}_{g}(\omega)$ are the Fourier transforms of $\dot{x}$ and $\ddot{u}_{g}(t)$, respectively. The symbol i denotes the imaginary unit. $H_{V}(\omega ; \Omega, h)$ can be expressed by

$$
H_{V}(\omega ; \Omega, h)=-\frac{\mathrm{i} \omega}{\Omega^{2}-\omega^{2}+2 \mathrm{i} h \Omega \omega}
$$

Equation (4) indicates that the earthquake input energy to damped linear elastic SDOF systems does not depend on the phase of input motions and this fact is well known (Lyon 1975, Kuwamura et al. 1994, Ordaz et al. 2003, Takewaki 2004a, b, 2005a, b, 2006, 2007a, b). It can also be understood from Equation (4) that the function $F(\omega)$ plays an important role in the evaluation of the earthquake input energy and may have some influence on the investigation of constancy of the earthquake input energy for structures with various model parameters. 
Assume that $\left|\ddot{U}_{g}(\omega)\right|$ is constant and equal to $\bar{A}$. Then Equation (4) can be reduced to

$$
E_{I} / m=\bar{A}^{2} \int_{0}^{\infty} F(\omega) \mathrm{d} \omega
$$

With the help of the residue theorem, the relation $\int_{0}^{\infty} F(\omega) \mathrm{d} \omega=1 / 2$ holds regardless of $\Omega$ and $h$ (Ordaz et al. 2003, Takewaki 2004a). Equation (6) is then reduced to

$$
E_{I} / m=\frac{1}{2} \bar{A}^{2}
$$

Equation (7) implies that the constancy of the earthquake input energy is related directly to the Fourier amplitude spectrum. This is not coincident with the theory due to Housner (1959) and Akiyama (1985) supporting the velocity response spectrum.

\section{Constancy of Earthquake Input Energy Based on Time-domain Analysis}

In the case where the Fourier amplitude spectrum of a ground acceleration is ideally constant, the discussion on constancy of earthquake input energy can be made in the time domain. The essence of this procedure will be shown here.

Consider a ground motion acceleration as the Dirac delta function.

$$
\ddot{u}_{g}(t)=\bar{A} \delta(t)
$$

where $\delta(t)$ is the Dirac delta function and the following relation holds

$$
\int_{-\infty}^{\infty} \ddot{u}_{g}(t) e^{-\mathrm{i} \omega t} d t=\int_{-\infty}^{\infty} \bar{A} \delta(t) e^{-\mathrm{i} \omega t} d t=\bar{A}
$$

Assume that the mass is at rest initially. The velocity change (initial velocity) of the mass may be evaluated by the impulse divided by the mass.

$$
\frac{1}{m} \int_{-\infty}^{\infty}\left\{-m \ddot{u}_{g}(t)\right\} d t=\int_{-\infty}^{\infty}\{-\bar{A} \delta(t)\} d t=-\bar{A}
$$

Because the constant Fourier amplitude spectrum of a ground acceleration corresponds to the Dirac delta function in the time domain (see Figure 2), the initial input energy may be given by 


$$
E_{I} / m=\frac{1}{2} \bar{A}^{2}
$$

This energy will be dissipated later by the viscous damping system.

\section{Proportionally Damped MDOF Structure}

Consider a proportionally damped multi-degree-of-freedom (MDOF) structure of the mass matrix $[M]$. Let $\{x\}$ denote the horizontal nodal displacements of masses relative to the ground and let $\{1\}$ denote the influence coefficient vector. Let $N$ denote the number of the horizontal nodal degrees of freedom of masses. The input energy to this MDOF structure may be described as

$$
\begin{aligned}
E_{I} & =-\int_{-\infty}^{\infty}\{\dot{x}\}^{T}[M]\{1\} \ddot{u}_{g} \mathrm{~d} t \\
& =-\int_{-\infty}^{\infty}\left[\frac{1}{2 \pi} \int_{-\infty}^{\infty}\{\dot{X}\}^{T} e^{\mathrm{i} \omega t} \mathrm{~d} \omega\right][M]\{1\} \ddot{u}_{g} \mathrm{~d} t \\
& =\int_{0}^{\infty}\left|\ddot{U}_{g}(\omega)\right|^{2} F_{M P}(\omega) \mathrm{d} \omega
\end{aligned}
$$

In Equation (12), $F_{M P}(\omega)$ may be defined by

$$
F_{M P}(\omega)=-\frac{1}{\pi}\left\{\operatorname{Re}\left[H_{V}\left(\omega ; \Omega_{i}, h_{i}\right)\right]\right\}^{T}[\Phi]^{T}[M]\{1\}
$$

where $\left\{H_{V}\left(\omega ; \Omega_{i}, h_{i}\right)\right\}, \Omega_{i}, h_{i},[\Phi]$ denote the velocity transfer function, the $i$-th undamped natural circular frequency, the $i$-th damping ratio and the modal matrix multiplied by the corresponding participation factors. By use of $\left\{H_{V}\left(\omega ; \Omega_{i}, h_{i}\right)\right\}$, the Fourier transform of the nodal velocity vector may be expressed as

$$
\{\dot{X}(\omega)\}=[\Phi]\left\{H_{V}\left(\omega ; \Omega_{i}, h_{i}\right)\right\} \ddot{U}_{g}(\omega)
$$

If $\left|\ddot{U}_{g}(\omega)\right|$ is constant $(=\bar{A})$ with respect to frequency, the input energy may be expressed as

$$
E_{I}=\bar{A}^{2} \int_{0}^{\infty} F_{M P}(\omega) \mathrm{d} \omega
$$

Substitution of Equation (13) into Equation (15) leads to

$$
E_{I}=-\bar{A}^{2}\left\{\int_{0}^{\infty} \frac{1}{\pi} \operatorname{Re}\left[H_{V}\left(\omega ; \Omega_{i}, h_{i}\right)\right] \mathrm{d} \omega\right\}^{T}[\Phi]^{T}[M]\{1\}
$$


With the help of the residue theorem in each mode, the input energy to the proportionally damped MDOF structure may result in

$$
E_{I}=\frac{1}{2} \bar{A}^{2}\{1\}^{T}[\Phi]^{T}[M]\{1\}=\frac{1}{2} \bar{A}^{2} \sum_{j=1}^{N} m_{j}
$$

Equation (17) implies that, if the Fourier amplitude is constant with respect to frequency, the input energy to the proportionally damped MDOF structure depends only on the total mass of the model.

The relation of Equation (17) can also be derived by the idea of Equations (8)-(11) in the time domain because the initial velocity $-\bar{A}$ is given simultaneously at all the masses for an ideal input with a constant Fourier amplitude spectrum (see Figure 2).

\section{Non-proportionally Damped MDOF Structure}

Consider a non-proportionally damped MDOF structure of mass matrix $[M]$, stiffness matrix $[K]$ and damping matrix $[C]$. The Fourier transformation of the equations of motion provides the Fourier transform $\{\dot{X}(\omega)\}$ of the nodal velocities.

$$
\{\dot{X}(\omega)\}=-\mathrm{i} \omega\left(-\omega^{2}[M]+\mathrm{i} \omega[C]+[K]\right)^{-1}[M]\{1\} \ddot{U}_{g}(\omega)=\left\{H_{V}(\omega)\right\} \ddot{U}_{g}(\omega)
$$

The input energy can then be computed by Eq.(12). The input energy without modal superposition may be computed by

$$
E_{I}=\int_{0}^{\infty} F_{M N}(\omega)\left|\ddot{U}_{g}(\omega)\right|^{2} \mathrm{~d} \omega
$$

where

$$
\begin{aligned}
& F_{M N}(\omega)=\frac{1}{\pi} \operatorname{Re}\left[\mathrm{i} \omega\{1\}^{T}[M]^{T}[Y(\omega)][M]\{1\}\right] \\
& {[Y(\omega)]=\left(-\omega^{2}[M]+\mathrm{i} \omega[C]+[K]\right)^{-1}}
\end{aligned}
$$

It should be noted that the computation of $[Y(\omega)]=\left(-\omega^{2}[M]+i \omega[C]+[K]\right)^{-1}$ for many frequencies is quite time-consuming especially for structures with many degrees of freedom.

Let us introduce the displacement transfer function $\left\{H_{D}(\omega)\right\}$ as 


$$
\{X(\omega)\}=\left\{H_{D}(\omega)\right\} \ddot{U}_{g}(\omega)
$$

where

$$
\left\{H_{D}(\omega)\right\}=-\left(-\omega^{2}[M]+\mathrm{i} \omega[C]+[K]\right)^{-1}[M]\{1\}
$$

When the damping coefficient can be divided into that $c_{i}^{(S)}$ due to structural damping and that $c_{i}^{(A)}$ due to passive dampers, the input energy to these passive dampers can be expressed by

$$
E_{I}^{(A)}=\frac{1}{2 \pi} \int_{-\infty}^{\infty}\left\{\sum_{i=1}^{N} \omega^{2} c_{i}^{(A)}\left|H_{D i}(\omega)-H_{D i-1}(\omega)\right|^{2}\right\}\left|\ddot{U}_{g}(\omega)\right|^{2} d \omega
$$

The energy transfer function for passive dampers may be expressed by

$$
F_{M N}^{(A)}(\omega)=\frac{1}{\pi}\left[\sum_{i=1}^{N} \omega^{2} c_{i}^{(A)}\left|H_{D i}(\omega)-H_{D i-1}(\omega)\right|^{2}\right]
$$

Because the constant Fourier amplitude spectrum of a ground acceleration corresponds to the Dirac delta function in the time domain, the initial input energy may be given by

$$
E_{I}=\frac{1}{2} \bar{A}^{2} \sum_{j=1}^{N} m_{j}
$$

It can then be derived that

$$
\int_{0}^{\infty} F_{M N}(\omega) \mathrm{d} \omega=\frac{1}{2} \sum_{j=1}^{N} m_{j}
$$

\section{Truncated Ground Motion and Frequency-Domain Analysis up to Arbitrary Time}

The frequency-domain approach is applicable to the earthquake input energy until an arbitrary time (Takewaki 2005c).

Consider again a damped linear elastic SDOF system as shown in Figure 1. The model is subjected to $\ddot{u}_{g}(t)$. The earthquake input energy in terms of the relative velocity $\dot{x}$ until an arbitrary time $t$ in the time domain may be expressed by 


$$
E_{I}^{r e l}(t) / m=-\int_{-\infty}^{t} \dot{x}(\tau) \ddot{u}_{g}(\tau) \mathrm{d} \tau
$$

Examples of this earthquake input energy in the relative sense (Uang and Bertero 1991) are shown in Figure 3 together with the earthquake input energy in the absolute sense given by

$$
E_{I}^{a b s}(t) / m=\int_{-\infty}^{t}\left\{\ddot{u}_{g}(\tau)+\ddot{x}(\tau)\right\} \dot{u}_{g}(\tau) \mathrm{d} \tau
$$

Let us introduce a ground acceleration $\ddot{u}_{g}^{*}(\tau ; t)$ truncated at time $t$ (see Figure 4) and the corresponding response relative velocity $\dot{x}^{*}(\tau ; t)$. The earthquake input energy in the relative sense until an arbitrary time $t$ may also be expressed by

$$
E_{I}^{r e l}(t) / m=-\int_{-\infty}^{\infty} \dot{x}^{*}(\tau ; t) \ddot{u}_{g}^{*}(\tau ; t) \mathrm{d} \tau
$$

It should be noted that $\ddot{u}_{g}^{*}(\tau ; t)$ and $\dot{x}^{*}(\tau ; t)$ include time $t$ as a parameter. Let $\ddot{U}_{g}^{*}(\omega ; t)$ and $\dot{X}^{*}(\omega ; t)$ denote the Fourier transform of $\ddot{u}_{g}^{*}(\tau ; t)$ and $\dot{x}^{*}(\tau ; t)$, respectively. Using the inverse Fourier transformation and Fourier transformation, the earthquake input energy until an arbitrary time $t$ in the frequency domain may be expressed by

$$
\begin{aligned}
E_{I}^{r e l}(t) / m & =-\int_{-\infty}^{\infty}\left[\frac{1}{2 \pi} \int_{-\infty}^{\infty} \dot{X}^{*}(\omega ; t) e^{\mathrm{i} \omega \tau} \mathrm{d} \omega\right] \ddot{u}_{g}^{*}(\tau ; t) \mathrm{d} \tau \\
& =-\frac{1}{2 \pi} \int_{-\infty}^{\infty}\left(\int_{-\infty}^{\infty} \ddot{u}_{g}^{*}(\tau ; t) e^{\mathrm{i} \omega \tau} \mathrm{d} \tau\right)\left\{H_{V}(\omega ; \Omega, h) \ddot{U}_{g}^{*}(\omega ; t)\right\} \mathrm{d} \omega \\
& =-\frac{1}{2 \pi} \int_{-\infty}^{\infty} \ddot{U}_{g}^{*}(-\omega ; t)\left\{H_{V}(\omega ; \Omega, h) \ddot{U}_{g}^{*}(\omega ; t)\right\} \mathrm{d} \omega \\
& =\int_{0}^{\infty}\left|\ddot{U}_{g}^{*}(\omega ; t)\right|^{2} \frac{1}{\pi}\left\{-\operatorname{Re}\left[H_{V}(\omega ; \Omega, h)\right]\right\} \mathrm{d} \omega \\
& =\int_{0}^{\infty}\left|\ddot{U}_{g}^{*}(\omega ; t)\right|^{2} F(\omega) \mathrm{d} \omega
\end{aligned}
$$

where $\dot{X}^{*}(\omega ; t)=H_{V}(\omega ; \Omega, h) \ddot{U}_{g}^{*}(\omega ; t)$ is used. It should be noted that Equation (30) includes $t$ not as a variable but as a parameter. Equation (30) is similar to the following relation derived by applying $t=t_{0}$ (duration of input) in Equation (30)

$$
E_{I}^{r e l}\left(t_{0}\right) / m=\int_{0}^{\infty}\left|\ddot{U}_{g}(\omega)\right|^{2} F(\omega) \mathrm{d} \omega
$$

This equation completely coincides with Equation (6). 


\section{Advantageous Feature of Frequency-domain Method (Bound Estimate)}

The time-domain method has an advantage that the idea explained in Equations (8)(11) can be applied to any elastic structures. On the other hand, the frequency-domain method has another advantage. Consider again an SDOF model. Assume that the Fourier amplitude spectrum of the ground acceleration is bounded by $A^{L} \leq\left|\ddot{U}_{g}(\omega)\right| \leq A^{U}$ (Figure 5(a)). It can then be shown that the earthquake input energy $E_{I}$ can be bounded by the following relation.

$$
\frac{1}{2} m\left(A^{L}\right)^{2} \leq E_{I} \leq \frac{1}{2} m\left(A^{U}\right)^{2}
$$

In another case, assume that the upper bound of $\left|\ddot{U}_{g}(\omega)\right|$ is given by the following form (see Figure 5(b)).

$$
\left|\ddot{U}_{g}(\omega)\right|^{U}=\left\{\begin{array}{lc}
A_{0}+A_{V}(\omega) & \left(0 \leq \omega \leq \omega_{C}\right) \\
A_{0} & \left(\omega_{C} \leq \omega\right)
\end{array}\right.
$$

Then the earthquake input energy $E_{I}$ can be bounded by the following relation.

$$
E_{I} \leq \frac{1}{2} m A_{0}^{2}+\int_{0}^{\omega_{C}} F(\omega)\left\{2 A_{0} A_{V}(\omega)+A_{V}(\omega)^{2}\right\} d \omega
$$

The second term in the right-hand side can be evaluated numerically. Since the earthquake ground motion has a lot of uncertainties, e.g. the occurrence probability, the intensity, the frequency contents and the duration, it appears difficult to specify its Fourier amplitude uniquely. However even in such a case, it may be possible to set an upper bound of its Fourier amplitude based on the database or theoretical background. These bounding relations, Eqs.(32) and (34), are expected to be useful for estimating the upper bound of the energy demand. This bound estimate is difficult in the time-domain method.

\section{Numerical Examples}

\subsection{Tall buildings}

10 to 100-story standard buildings as shown in Figure 6 are considered. The plan of these buildings is $40 \mathrm{~m} \times 40 \mathrm{~m}$ and the mass per unit floor is $1.28 \times 10^{6}(\mathrm{~kg})$. The buildings 
are designed so that the fundamental natural period of the model is given by $T_{1}=0.1 \mathrm{~N}$ ( $N$ : number of stories) and the lowest eigenmode of the model becomes the straight line. The structural damping ratio is specified as 0.02. Two kinds of buildings are considered, one without passive viscous dampers and the other with passive viscous dampers. The amount of the passive viscous dampers is determined from the condition that the additional damping ratio attains 0.08. It is well known that the passive dampers are not effective in upper stories in tall buildings. This effect is included here by introducing the effective coefficients. These effective coefficients multiplied on the original damping coefficients are set as 0.9 in the first story and 0.5 in the topmost story (linear interpolation). The additional damping ratio 0.08 is evaluated in the case of the effective coefficients=1.0.

The energy transfer functions divided by the total mass for these $20,40,60,80,100$ story buildings without and with passive viscous dampers are shown in Figure 7(a), (b). Those with passive viscous dampers under consideration of the effective coefficients are shown in Figure 7(c). It can be observed that, because the passive dampers in lower stories are effective for structural control and the overall bending deformation does not affect so much those dampers, the difference between Figures 7(b) and 7(c) is small. As the amount of damping increases, the amplitude of the energy transfer function at the fundamental natural frequency becomes smaller. However, it should be noted that, for buildings with a specified number of stories, the area of energy transfer functions is constant and the input energy exhibits a stable characteristic.

Figure 8 shows the comparison of energy transfer functions divided by the total mass of overall models and those due to passive dampers. The energy transfer functions of subassemblages have been discussed in Reference (Takewaki 2007b) and Equation (24) has been used for computation. It can be observed that most parts are governed by the passive dampers in this case. This shows that the expression in terms of energy transfer functions is appropriate for clear understanding of the location of principal energy consumption.

\subsection{Base-isolated buildings}

Consider next mid-rise and high-rise base-isolated buildings. In Japan, not a few 
high-rise base-isolated buildings have been constructed to meet the requirements on safety and serviceability. In order to present the input energy characteristics to mid and high-rise base-isolated buildings, energy transfer functions for these buildings have been investigated. The plan of the buildings is $40 \mathrm{~m} \times 40 \mathrm{~m}$ as in the case of tall buildings in the previous section and the mass per unit floor is $1.28 \times 10^{6}(\mathrm{~kg})$. The masses of super buildings are shown in Table 1 and the mass of the isolation floor is specified as three times the floor mass in the super-building. The natural-rubber isolator of diameter $800(\mathrm{~mm})$ is used. The vertical and horizontal stiffnesses of the isolator are $4.03 \times 10^{9}[\mathrm{~N} / \mathrm{m}]$ and $1.42 \times 10^{6}[\mathrm{~N} / \mathrm{m}]$, respectively.

The super-buildings are designed so that the fundamental natural period of the model with fixed base is given by $T_{1}=0.1 N$ ( $N$ : number of stories) and the lowest eigenmode of the model with fixed base becomes the straight line. On the other hand, the horizontal stiffness of the isolation story is determined from the hybrid inverse formulation (Takewaki 1998) in which the fundamental natural period of the overall model attains a specified value (see Table 2) for a given super-building. The damping coefficient of the viscous-type damper in the isolation story is determined from the requirement that the nominal lowestdamping ratio of the overall model attains 0.1. The structural damping ratio of the superbuilding is given as 0.02 for the fixed-base model. It should be noted that a 2DOF model is used in this hybrid inverse formulation only. Because the compressive stress of the isolator under gravity loading has also to satisfy a certain constraint (see Table 1 as for the minimum number of isolators), friction-type bearings are used, i.e. a certain part of gravity load is sustained by the friction-type bearings (see Table 2 as for the necessary number of frictiontype bearings). Due to an extremely small friction coefficient of the friction-type bearings, the dissipation energy in the friction-type bearings has been ignored.

The energy transfer functions divided by the total mass for 10, 20, 30, 40, 50-story base-isolated buildings (see Figure 6) are shown in Figure 9. As stated before, the areas of energy transfer functions divided by the total mass are constant. In Figure 9, both the overall energy transfer function and that corresponding to the damper in the isolation story (Equation (24) with $N=1$ ) are plotted. It can be seen that the most part of the energy transfer function is governed by the quantity due to the damper in the isolation story. 


\subsection{Energy spectra for recorded ground motions}

In order to investigate the property of energy spectra $\sqrt{2 E_{I} / M}$ ( $M$ : total mass of the building) (see Akiyama 1985, Ordaz et al. 2003) for recorded ground motions, six recorded ground motions are used, i.e. El Centro NS (Imperial Valley 1940), Taft EW (Kern County 1952), Hachinohe EW 1968 (Tokachi-oki 1968) (far-field motion), JMA Kobe NS (Hyogoken-Nanbu 1995) (near-field motion), KBU NS (Hyogoken-Nanbu 1995) (near-field motion), Port of Tomokomai EW (Tokachi-oki 2003) (long-period ground motion). The Fourier amplitude spectra of these ground motions are shown in Figure 10.

Figure 11(a) shows the energy spectra for above-mentioned tall buildings with respect to their fundamental natural periods for El Centro NS 1940. It can be observed that the energy spectra exhibit a stable property regardless of the inclusion of passive dampers except the models of 10, 20 and 30 stories. After further investigation, it was found that the Fourier amplitude spectra corresponding to the fundamental natural frequencies (natural periods=1, 2, 3sec) of the models of 10, 20 and 30 stories exhibit larger values compared with other frequency ranges. Figure 11(b) indicates the energy spectra of above-mentioned base-isolated buildings with respect to their fundamental natural periods for El Centro NS 1940. It can be found that the energy spectra for base-isolated buildings exhibit a good correlation with those for tall buildings as far as the fundamental natural period is the same.

Figures 12(a), (b), 13(a), (b), 14(a), (b), 15(a), (b) and 16(a), (b) show those for Taft EW 1952, Hachinohe EW 1968, JMA Kobe NS 1995, KBU NS 1995, Port of Tomokomai EW 2003, respectively. It can be found that Port of Tomokomai EW 2003 has a strong effect on the response of the models with long fundamental natural periods (Ariga et al. 2006). The irregular phenomena in the models of 10, 20 and 30 stories for Hachinohe EW 1968 and KBU NS 1995 are due to the same reason stated above (small magnitude of Fourier amplitude spectra in the long-period range). It can be concluded that, although the energy spectra depend on the intensity of ground motions, the energy spectra for baseisolated buildings exhibit a good correspondence to some extent with those for tall buildings as far as the fundamental natural period is the same. 


\section{Conclusions}

The conclusions may be stated as follows.

(1) The equi-area property of the energy transfer function $F(\omega)$ of an SDOF model guarantees that, if the Fourier amplitude spectrum of a ground acceleration is uniform with respect to frequency, the constancy of the earthquake input energy holds strictly. Otherwise, its constancy is not guaranteed. However this equi-area property guarantees the stable characteristic of the earthquake input energy to elastic structures as almost constant.

(2) This property on the energy transfer function in more general structural models can be proved by the time-domain method for an idealized model of input motions with a constant Fourier amplitude spectrum. This idealized input model corresponds to the Dirac delta function in the time domain and the input energy can be characterized by the initially given kinetic energy depending only on the total mass.

(3) As for tall buildings including viscous or visco-elastic dampers, the input energy to the buildings is approximately constant regardless of the quantity of those viscous or viscoelastic dampers. This property is also guaranteed by the equi-area property of the energy transfer function and leads to an advantageous feature that, if the energy consumption in the passive dampers increases, the input energies to the buildings can be reduced effectively. The same advantage can be stated for base-isolated buildings.

(4) The frequency-domain method is appropriate for bound analysis of input energy in which the lower and/or upper bounds of the Fourier amplitude spectrum of input motions are specified. Dual use of the frequency-domain and time-domain techniques may be preferable in the advanced seismic analysis for robuster design.

(5) Although the energy spectra depend on the intensity of ground motions, the energy spectra for base-isolated buildings exhibit a good correspondence to some extent with those for tall buildings as far as the fundamental natural period is the same. 


\section{Acknowledgements}

Part of the present work is supported by the Grant-in-Aid for Scientific Research of Japan Society for the Promotion of Science (No.18360264). This support is greatly appreciated.

\section{References}

Akiyama, H. (1985). Earthquake Resistant Limit-State Design for Buildings. University of Tokyo Press, Tokyo, Japan.

Ariga, T., Kanno, Y., and Takewaki, I. (2006). Resonant behavior of base-isolated high-rise buildings under long-period ground motions, The Structural Design of Tall and Special Buildings, 15(3), 325-338.

Housner, G.W. (1959). Behavior of structures during earthquakes. Journal of the Engineering Mechanics Division, ASCE, 85(4), 109-129.

Kuwamura, H., Kirino, Y., and Akiyama, H. (1994). Prediction of earthquake energy input from smoothed Fourier amplitude spectrum. Earthquake Engineering and Structural Dynamics, 23, 1125-1137.

Leger, P., and Dussault, S. (1992). Seismic-energy dissipation in MDOF structures. Journal of Structural Engineering, ASCE, 118(5) 1251-1269.

Lyon, R.H. (1975). Statistical Energy Analysis of Dynamical Systems, The MIT Press, Cambridge, MA.

Ordaz, M., Huerta, B., and Reinoso, E. (2003). Exact computation of input-energy spectra from Fourier amplitude spectra. Earthquake Engineering and Structural Dynamics, 32, 597-605.

Takewaki, I. (1998). Hybrid inverse eigenmode problem for a shear building supporting a finite-element subassemblage, Journal of Vibration and Control, 4(4), 347-360.

Takewaki, I. (2004a). Bound of earthquake input energy, Journal of Structural Engineering, ASCE, 130(9), 1289-1297.

Takewaki, I. (2004b). Frequency domain modal analysis of earthquake input energy to highly damped passive control structures, Earthquake Engineering and Structural Dynamics; 33(5): 575-590. 
Takewaki, I. (2005a). Frequency domain analysis of earthquake input energy to structurepile systems, Engineering Structures, 27(4), 549-563.

Takewaki, I. (2005b). Bound of earthquake input energy to soil-structure interaction systems, Soil Dynamics and Earthquake Engineering, 25(7-10), 741-752.

Takewaki, I. (2005c). Closure to the discussion by Ali Bakhshi and Hooman Tavallali to 'Bound of earthquake input energy, J. of Structural Engineering, ASCE, 130(9), 12891297, 2004’ by I. Takewaki, 131(10), 1643-1644.

Takewaki, I. (2006). Critical Excitation Methods in Earthquake Engineering, Elsevier, 268pages, December 2006.

Takewaki, I. (2007a). Closed-form sensitivity of earthquake input energy to soil-structure interaction system, Journal of Engineering Mechanics, ASCE, 133(4), 389-399.

Takewaki, I. (2007b). Earthquake input energy to two buildings connected by viscous dampers, Journal of Structural Engineering, ASCE, 133(5), 620-628.

Uang, C.M., and Bertero, V.V. (1990). Evaluation of seismic energy in structures. Earthquake Engineering and Structural Dynamics, 19, 77-90.

Zahrah, T.F., and Hall, W.J. (1984). Earthquake energy absorption in SDOF structures. Journal of Structural Engineering, ASCE, 110(8) 1757-1772. 
Table 1 Parameters determined from the condition under gravity loading

\begin{tabular}{|c|c|c|c|c|}
\hline & $\begin{array}{c}\text { Total mass of } \\
\text { building } \\
(\mathrm{kg})\end{array}$ & $\begin{array}{c}\text { Stiffness of } \\
\text { building (SDOF } \\
\text { model) (N/m) }\end{array}$ & $\begin{array}{c}\text { Required minimum } \\
\text { number of isolators from } \\
\text { compressive stress } \\
\text { condition under gravity } \\
\text { loading }\end{array}$ & $\begin{array}{c}\text { Horizontal } \\
\text { stiffness of } \\
\text { isolation story } \\
(\mathrm{N} / \mathrm{m})\end{array}$ \\
\hline 10-story & $1.28 \times 10^{7}$ & $5.05 \times 10^{8}$ & 17 & $2.42 \times 10^{7}$ \\
\hline 20-story & $2.56 \times 10^{7}$ & $2.53 \times 10^{8}$ & 34 & $4.83 \times 10^{7}$ \\
\hline 30-story & $3.84 \times 10^{7}$ & $1.68 \times 10^{8}$ & 51 & $7.25 \times 10^{7}$ \\
\hline 40-story & $5.12 \times 10^{7}$ & $1.26 \times 10^{8}$ & 68 & $9.66 \times 10^{7}$ \\
\hline 50-story & $6.42 \times 10^{7}$ & $1.01 \times 10^{8}$ & 85 & $1.21 \times 10^{8}$ \\
\hline
\end{tabular}

Table 2 Parameters determined from the natural period condition

\begin{tabular}{|c|c|c|c|}
\hline & $\begin{array}{c}\text { Fundamental natural } \\
\text { period (s) (Isolator only) }\end{array}$ & $\begin{array}{c}\text { Allowable maximum } \\
\text { number of isolators from } \\
\text { natural period condition }\end{array}$ & $\begin{array}{c}\text { Fundamental natural } \\
\text { period (s) (Isolator + } \\
\text { friction damper) }\end{array}$ \\
\hline 10-story & 5.29 & $\begin{array}{c}17 \\
\text { (no friction damper) }\end{array}$ & 5.29 \\
\hline 20 -story & 5.25 & $\begin{array}{c}25 \\
(26.5 \% \text { friction damper) }\end{array}$ & 5.63 \\
\hline 30 -story & 5.60 & $\begin{array}{c}32 \\
(37.3 \% \text { friction damper) }\end{array}$ & 6.47 \\
\hline 40 -story & 6.15 & $\begin{array}{c}40 \\
(41.2 \% \text { friction damper) }\end{array}$ & 7.24 \\
\hline 50 -story & 6.82 & $\begin{array}{c}47 \\
(44.7 \% \text { friction damper) }\end{array}$ & 8.01 \\
\hline
\end{tabular}

Free-body diagram

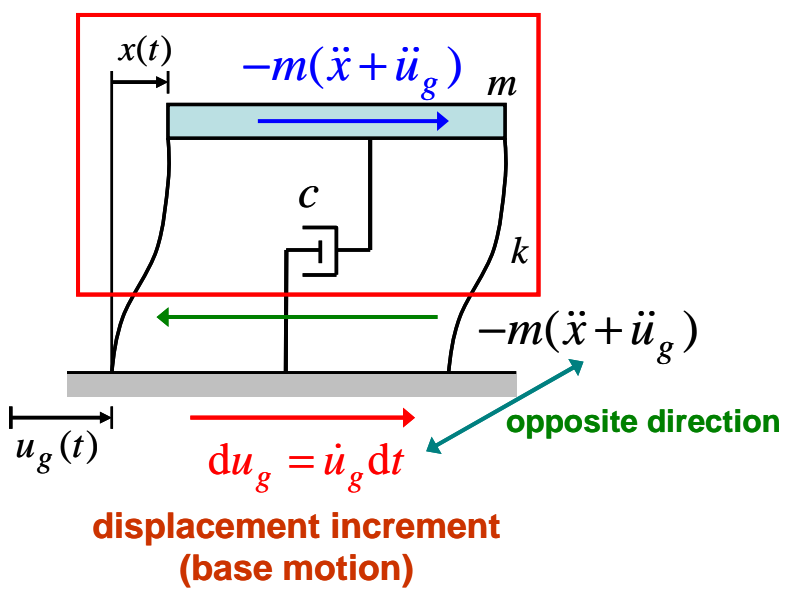

Figure 1: Single-degree-of-freedom model subjected to ground motion 

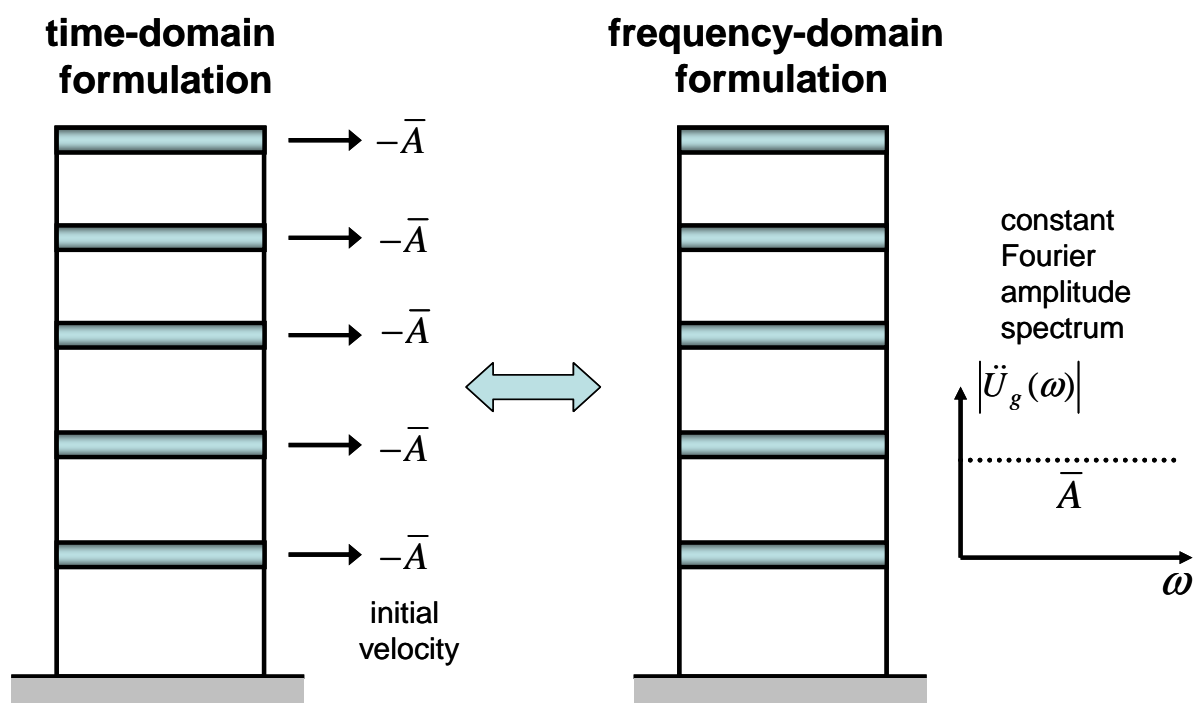

Figure 2: Correspondence of time and frequency-domain dual formulations
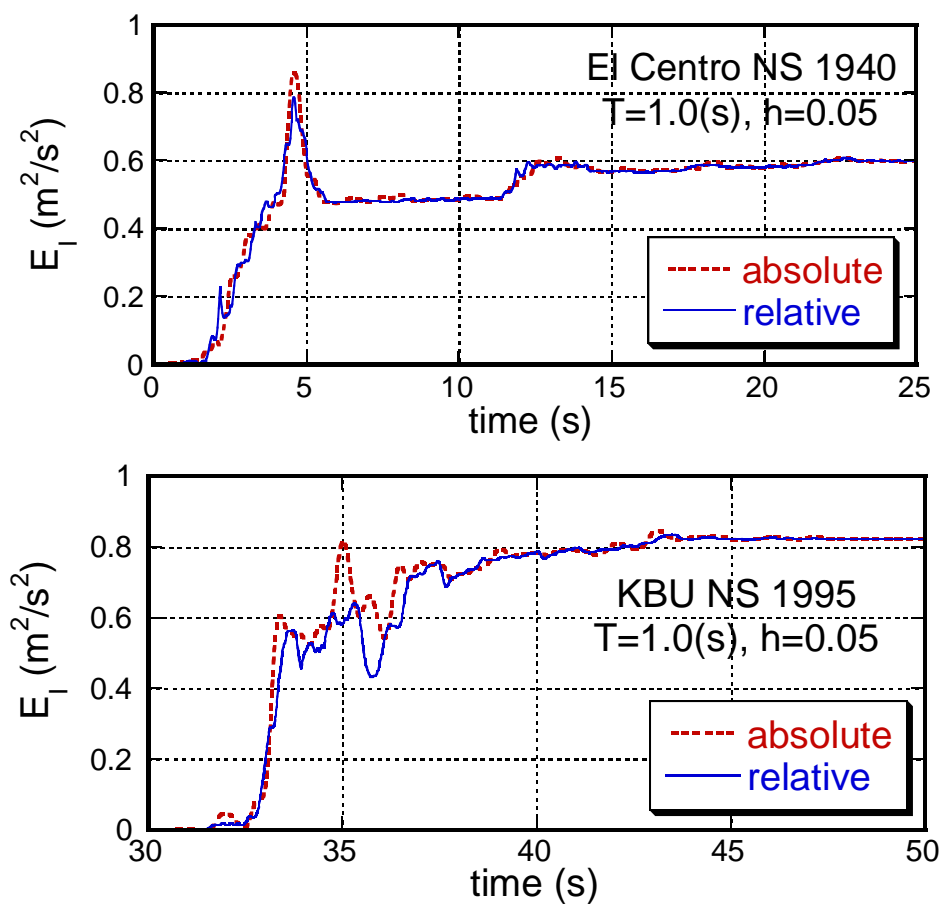

Figure 3: Time history of input energies $E_{I}^{r e l}(t) / m, E_{I}^{a b s}(t) / m$ per unit mass for El Centro NS (Imperial Valley 1940) and KBU NS (Hyogoken-Nanbu 1995) 


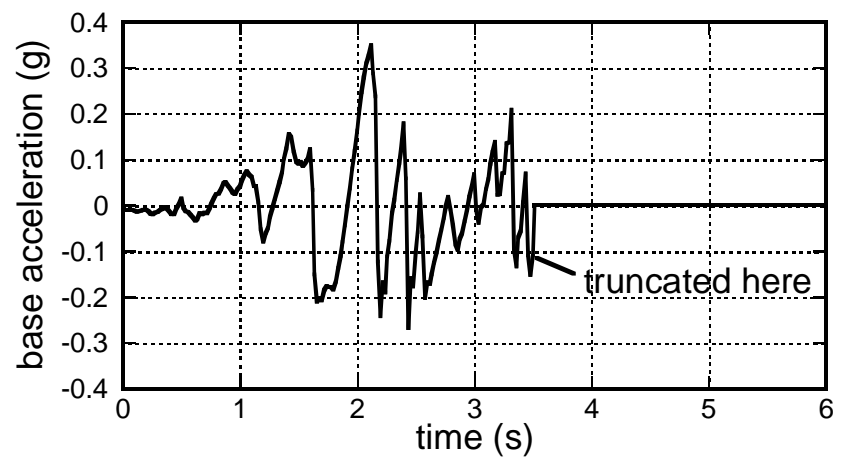

Figure 4: Ground acceleration truncated at time $t$

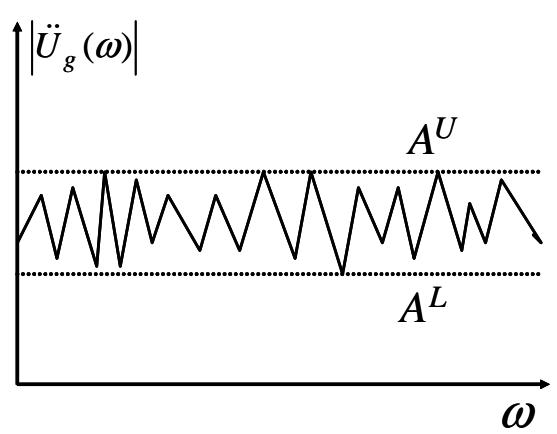

(a) simple model

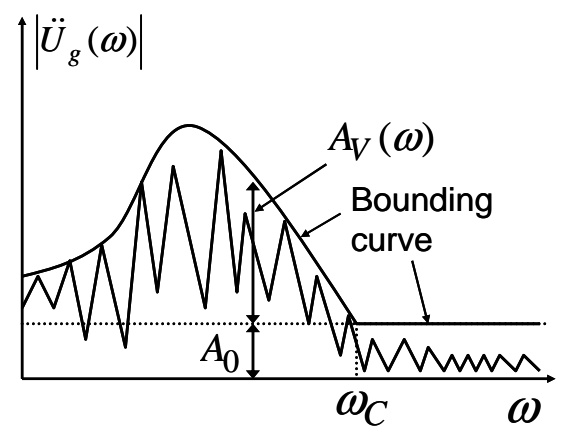

(b) realistic model

Figure 5: Bounding of Fourier amplitude spectrum of ground acceleration

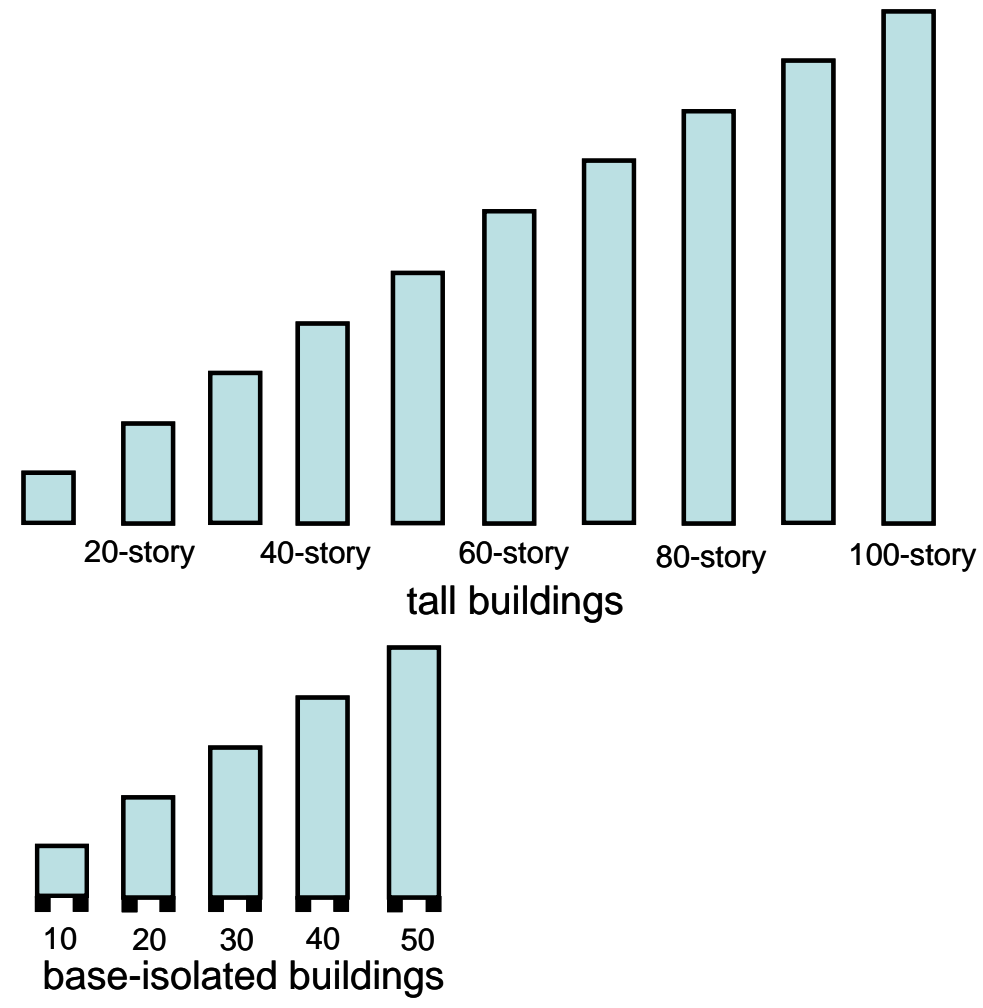

Figure 6: Tall buildings of 10 to 100 stories and base-isolated buildings of 10 to 50 stories 


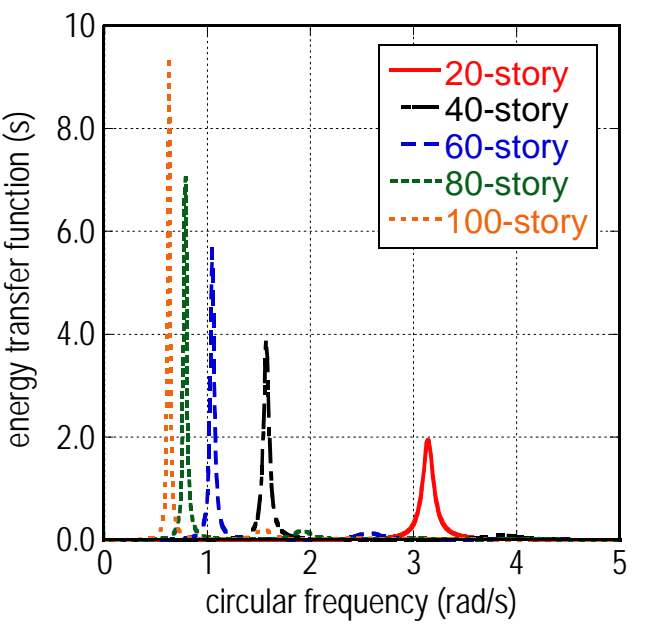

(a) without passive dampers

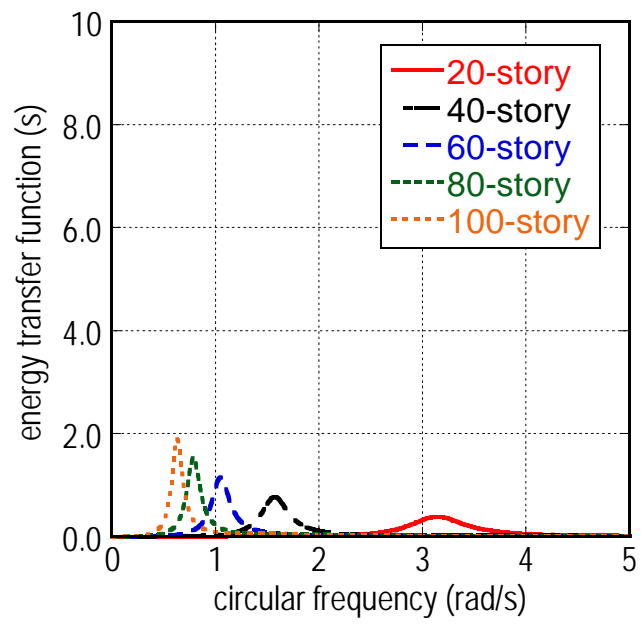

(b) with passive dampers

(ignoring damper effective coefficient)

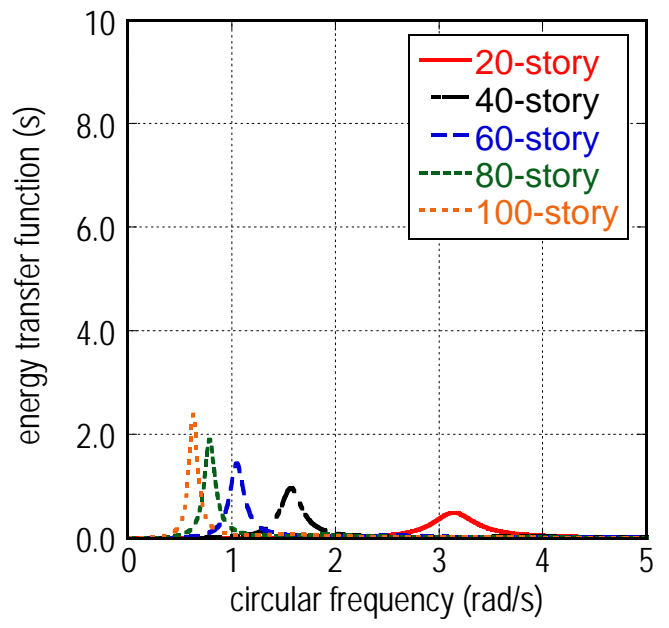

(c) with passive dampers (including damper effective coefficient)

Figure 7: Energy transfer functions for tall buildings without and with passive dampers 


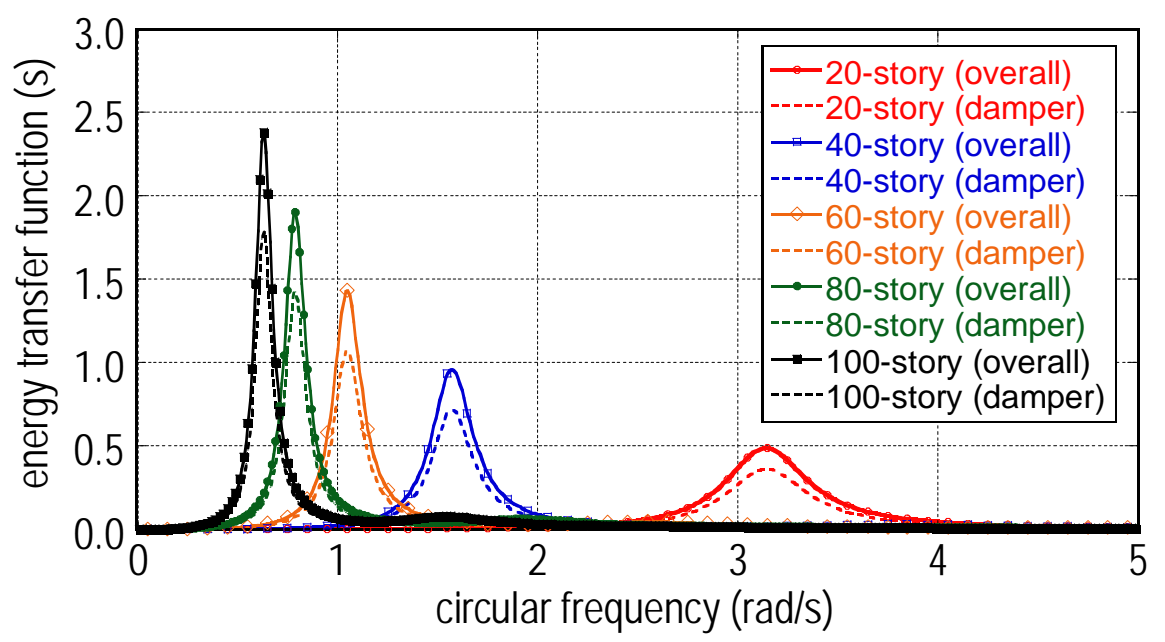

Figure 8: Energy transfer functions for overall models and passive dampers in tall buildings

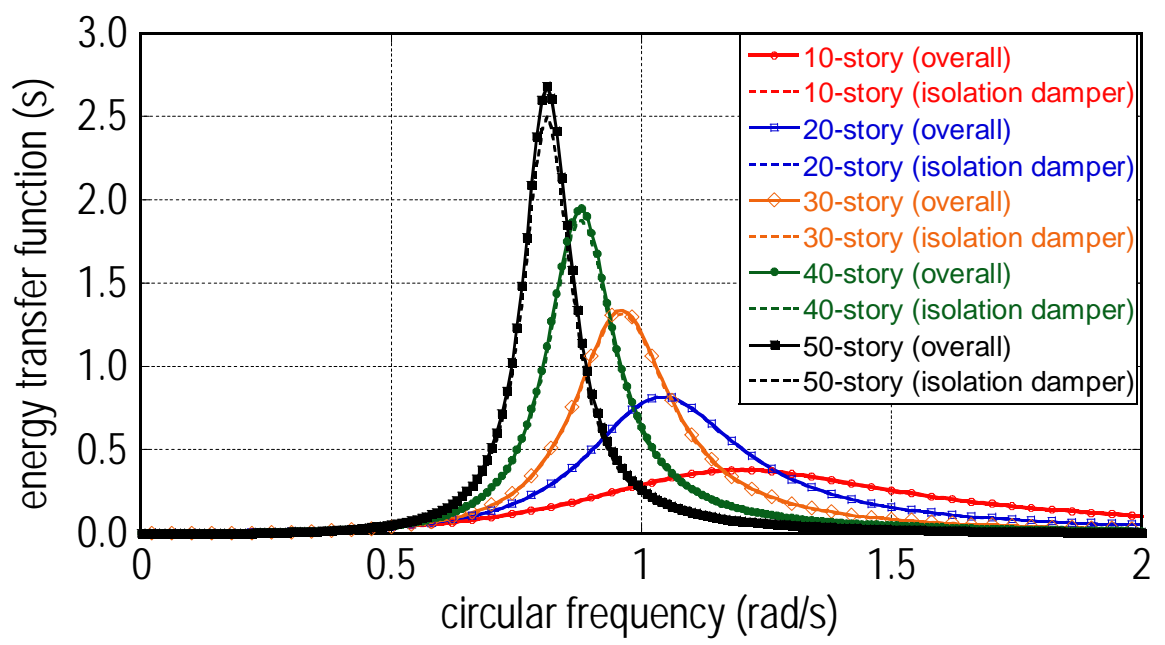

Figure 9: Energy transfer functions for overall models and isolation dampers in base-isolated buildings 

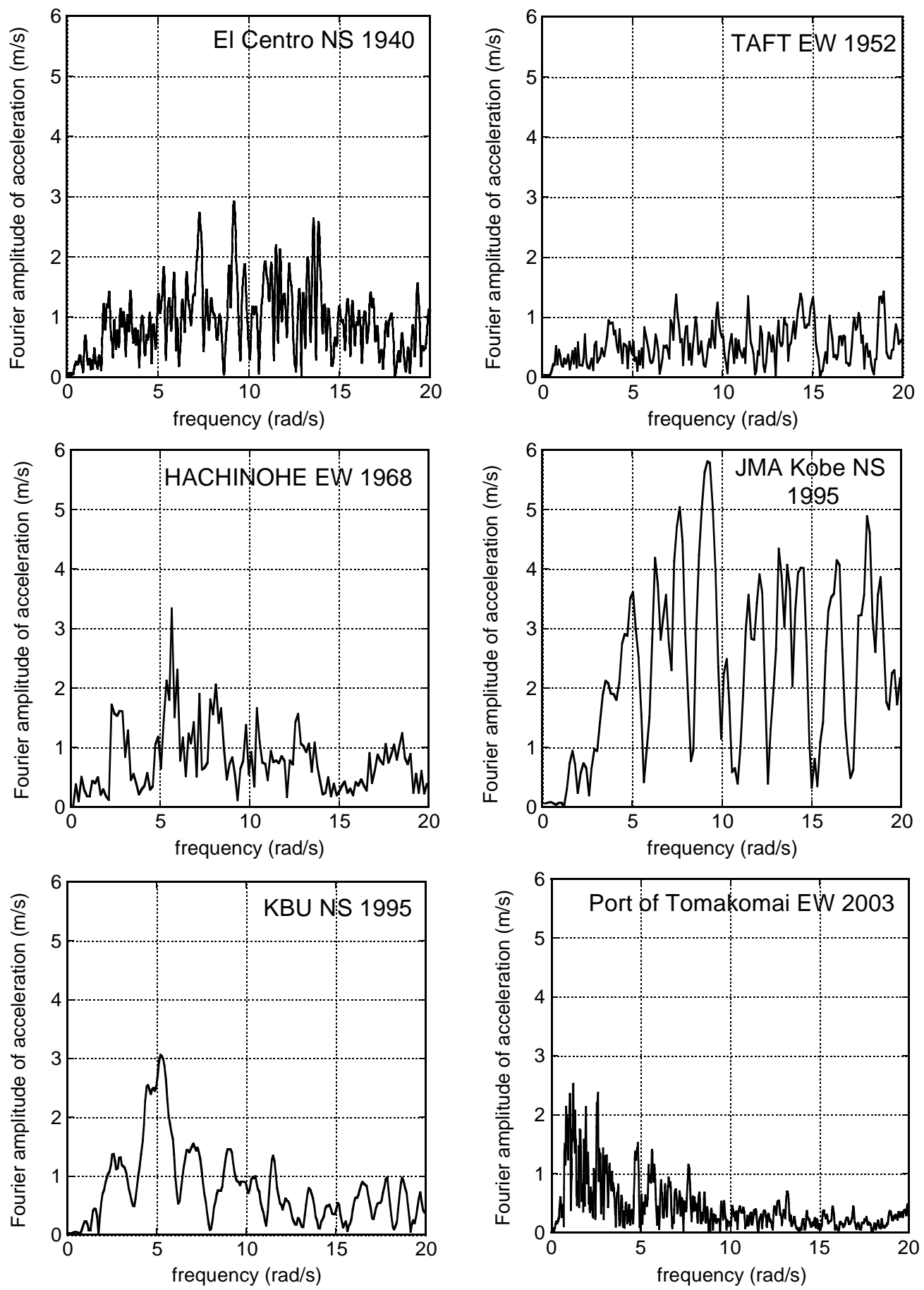

Figure 10: Fourier amplitude spectra for El Centro NS 1940, Taft EW 1952, Hachinohe EW 1968, JMA Kobe NS 1995, KBU NS 1995, Port of Tomokomai EW 2003. 


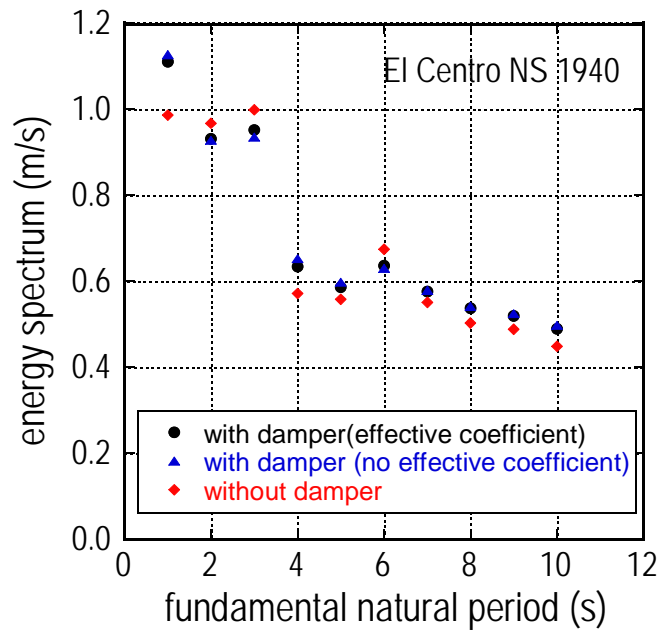

(a) tall building

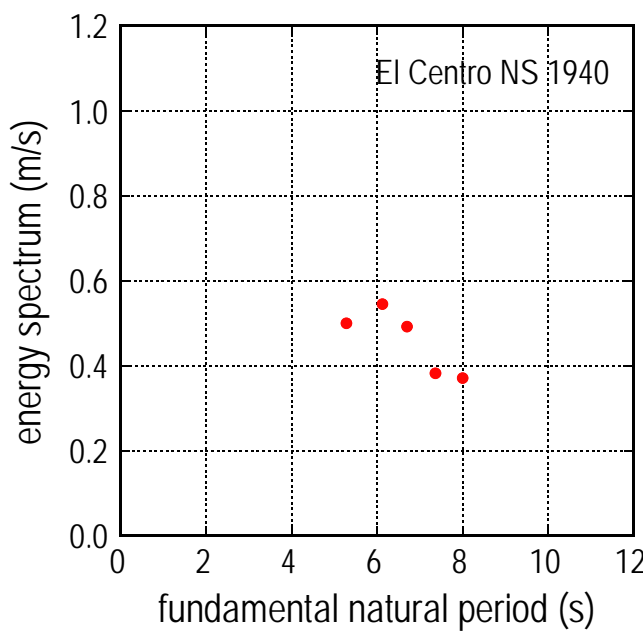

(b) base-isolated building

Figure 11: Energy spectra for tall buildings and base-isolated buildings (El Centro NS 1940)

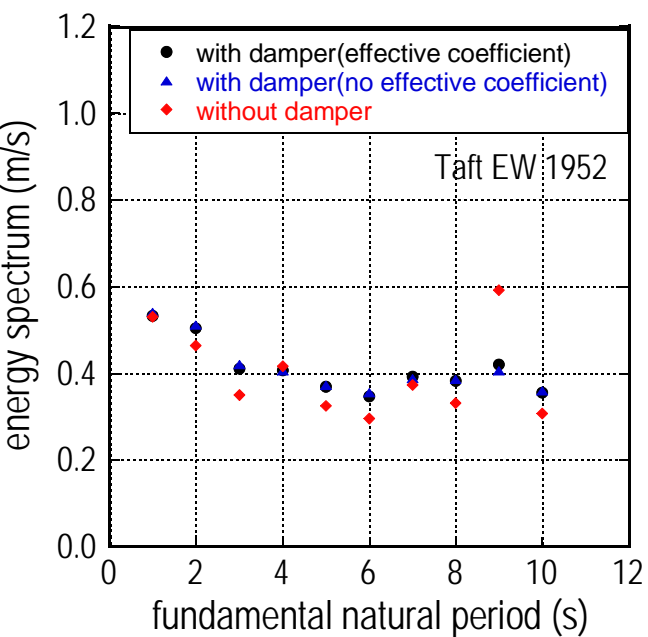

(a) tall building

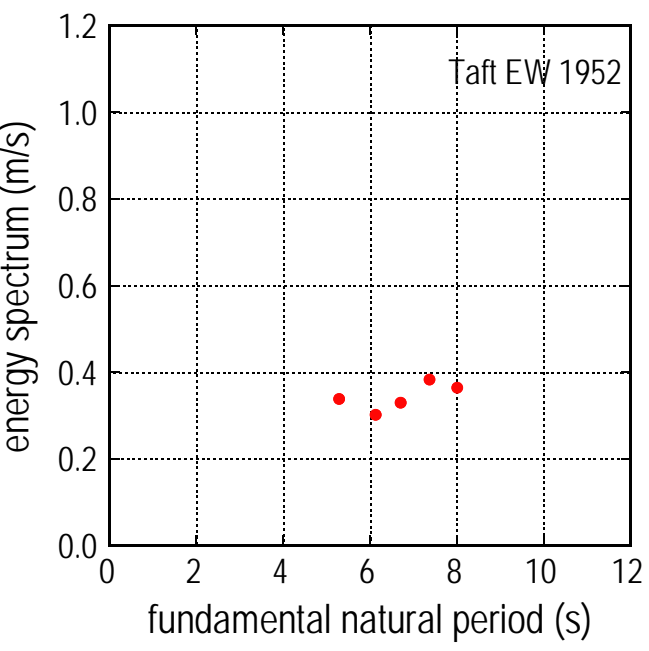

(b) base-isolated building

Figure 12: Energy spectra for tall buildings and base-isolated buildings (Taft EW 1952)

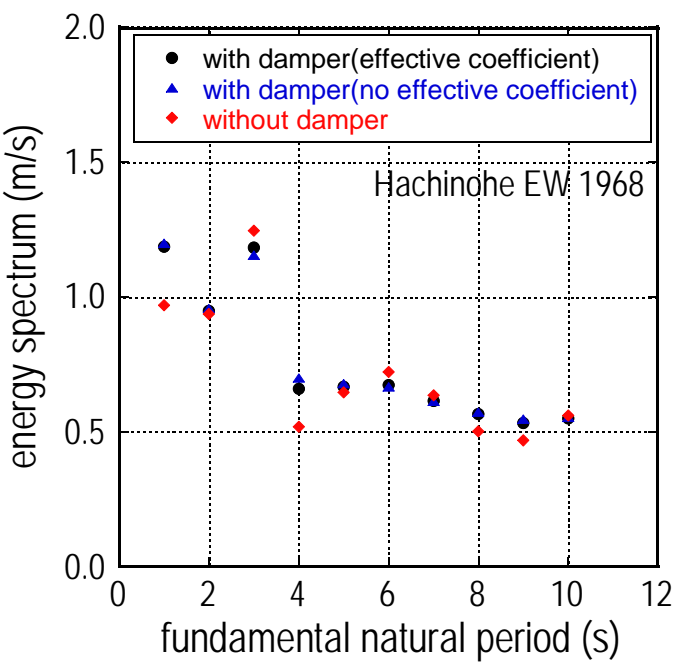

(a) tall building

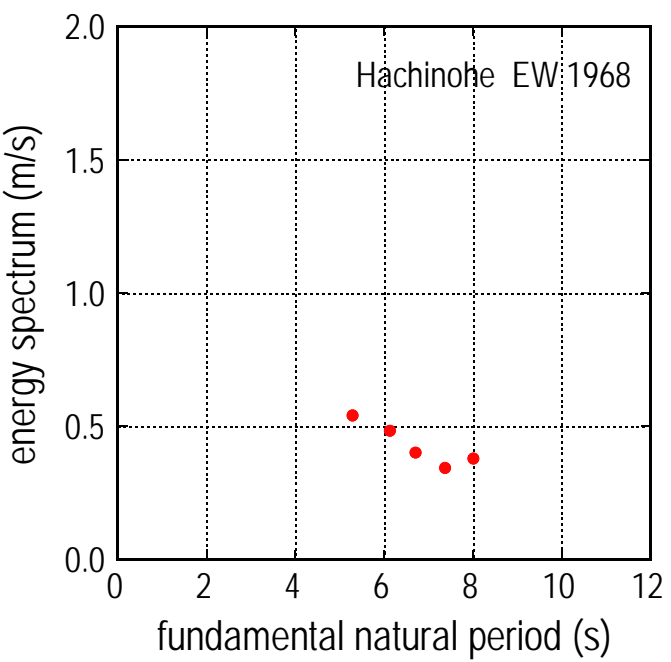

(b) base-isolated building

Figure 13: Energy spectra for tall buildings and base-isolated buildings (Hachinohe EW 1968) 


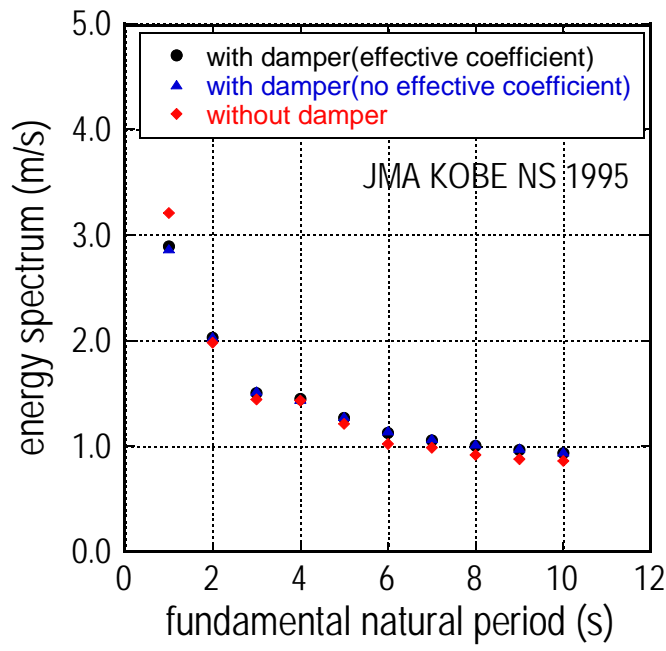

(a) tall building

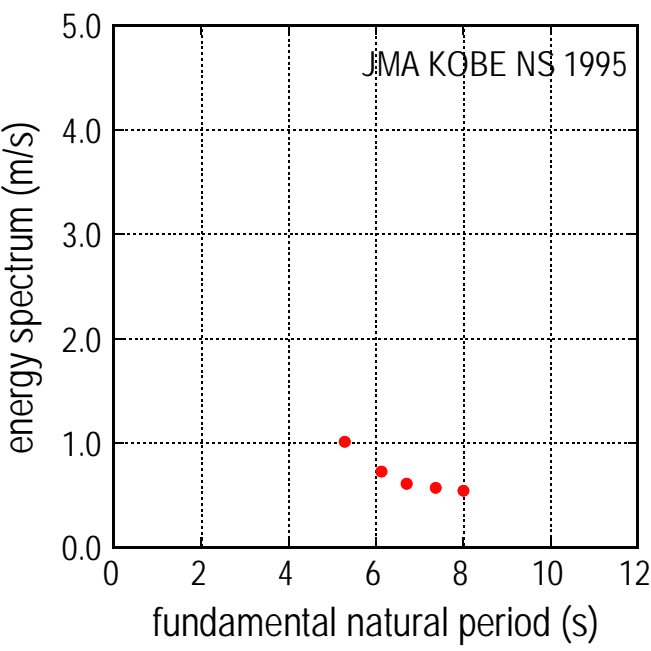

(b) base-isolated building

Figure 14: Energy spectra for tall buildings and base-isolated buildings (JMA Kobe NS 1995)

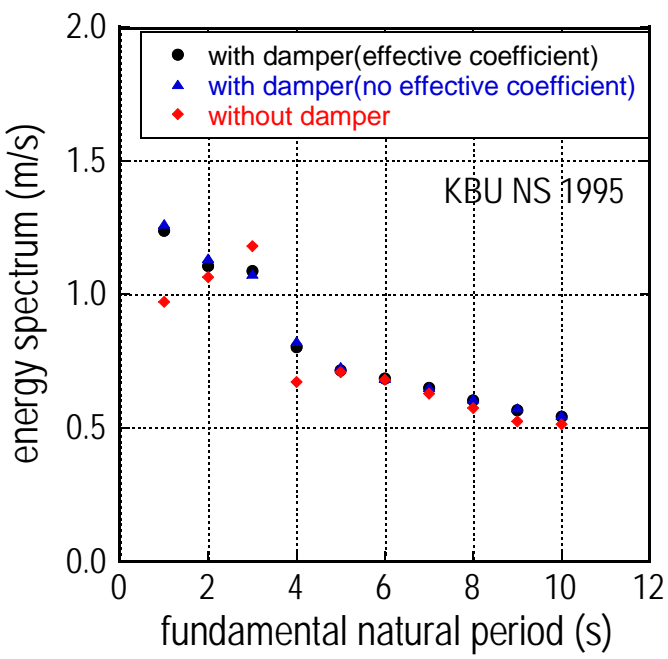

(a) tall building

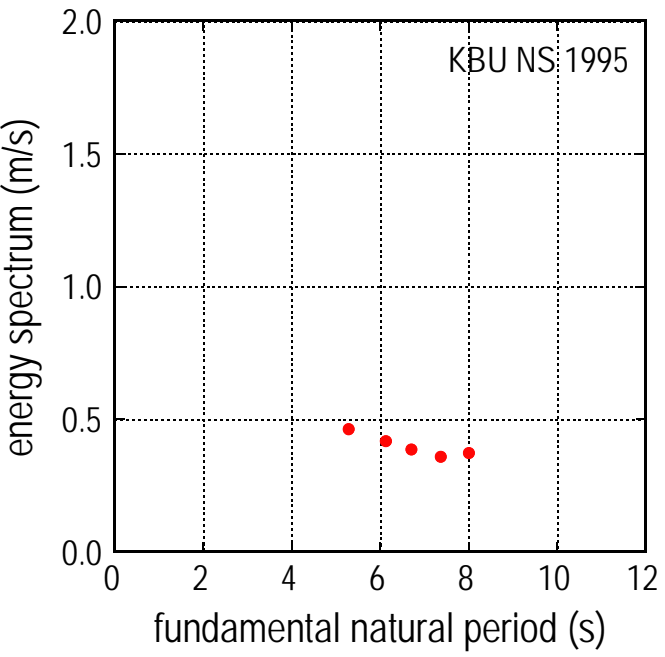

(b) base-isolated building

Figure 15: Energy spectra for tall buildings and base-isolated buildings (KBU NS 1995)

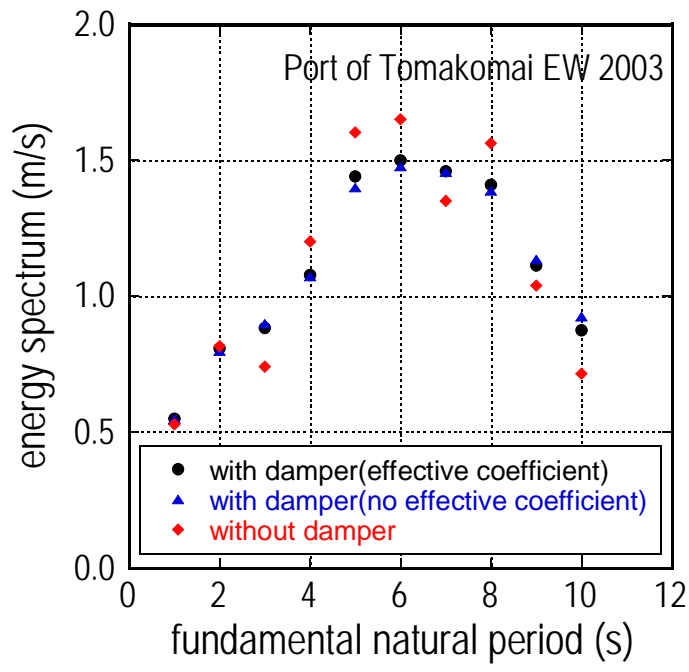

(a) tall building

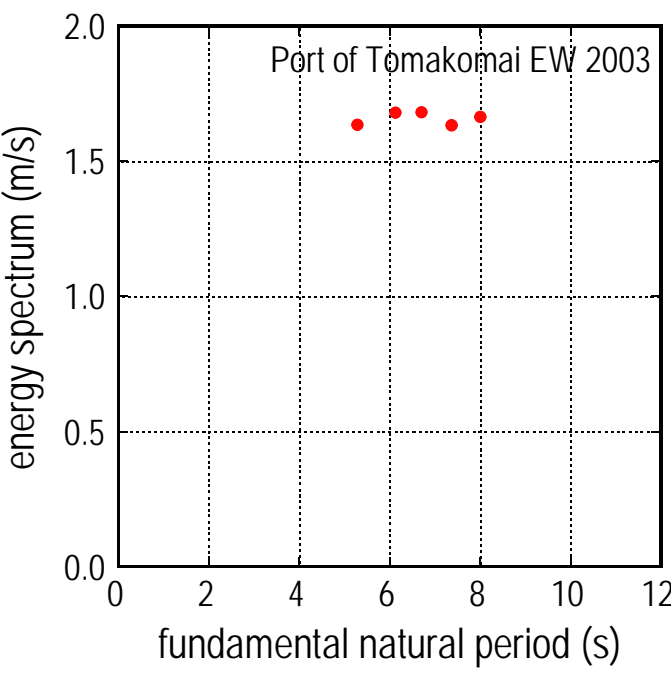

(b) base-isolated building

Figure 16: Energy spectra for tall buildings and base-isolated buildings (Port of Tomakomai EW 2003) 